\title{
Management of bauxite residue in a temperate climate using mud-farming techniques
}

\author{
MB Willan Golder Associates (UK) Ltd, UK \\ GS Ghataora The University of Birmingham, UK
}

\begin{abstract}
The management of water within the mining waste industry is one of the most critical factors affecting operators today. Long-term sustainable management will both increase the volume of waste which can be stored in a given area and decrease the effect on sometimes fragile water supplies. One often overlooked technique, primarily used in the alumina refining industry, is the mechanical consolidation and densification of waste bauxite residue (also known as 'red mud' due to its colour) in a process known as mud-farming. This technique provides a simple, less technology-dependent solution as it is carried out by relatively inexpensive mechanical plant. Whilst a number of studies have examined the effectiveness of mud-farming, these studies have been carried out in the comparatively arid climate of South West Australia. Given that this technique may be of interest to the wider mine waste industry, a study into the observed benefits of mud-farming techniques within a temperate climate has been conducted. This study has focused on the mud-farming operations currently carried out at the Rusal Aughinish Alumina facility, near Limerick, Ireland. The study makes use of both historical site investigation data and the results from a site investigation carried out in 2014, using cone penetration testing as well as a complimentary laboratory testing programme. The results of this study demonstrate that the application of mud-farming techniques has led to increases in the both the undrained shear strength and the density of the bauxite residue which will ultimately enable increased capacity at the facility. Furthermore, this study identifies a number of issues arising for the use of standard geotechnical laboratory testing of bauxite residue, including the potential to miscalculate moisture content due to the presence of amorphous particle, and undrained shear strength.
\end{abstract}

\section{Introduction}

Tailings disposal has been identified as the primary source of environmental impact for many mining operations (Vick 1990). As tailings is a waste product with little or no financial value, the disposal thereof should be economically viable whilst meeting regulatory, site and safety standards.

One of the largest costs associated with the surface disposal of tailings is the initial construction of the tailings management facility (TMF). Minimising the footprint of a TMF, however, is a function of the density of the deposited tailings as well as its associated shear strength which determines how high the facility may be safely raised. Numerous techniques have been, or are under development to improve the density and/or strength of tailings to achieve greater storage capacities within a given footprint area. These include:

- The development of thickener technology and slurry pumps to produce and transport tailings slurries at lower water contents.

- The deposition of tailings material in thin layers (typically less than $200 \mathrm{~mm}$ ) to increase the effect of evaporative drying.

- The use of electrokinetic dewatering techniques to remove water from deposited tailings.

- The use of polymers to aid pumping of thicker slurries and/or increase the bleeding of water from the slurry on deposition. 
Several of the above dewatering techniques are not appropriate for operations in developing countries or where the cost benefits of a smaller facility are outweighed by the expensive purchasing and operating costs associated with these technologies. One often overlooked dewatering method, primarily used in the alumina $\left(\mathrm{Al}_{2} \mathrm{O}_{3}\right)$ refining industry, is to mechanically consolidate and densify the waste bauxite residue (also known as 'red mud' due to its colour) in a process known as mud-farming. This technique provides a simpler, less technology-dependent solution due to the farming being carried out by comparatively inexpensive earth-moving equipment. This method may thus be of benefit for operations where the use of advanced and expensive technology-dependent process and methods are not viable. A number of studies (Li et al. 2011; Smirk \& Jackson 2010; Munro \& Smirk 2012) have examined the effectiveness of mud-farming. However, these studies have been carried out on facilities located in the relatively arid climate of South West Australia (mean annual precipitation of $867.5 \mathrm{~mm}, 71 \%$ of which falls during a four-month period, and mean maximum temperature of $23.3^{\circ} \mathrm{C}$, (Australian Government Bureau of Meteorology 2014)).

Given that no studies are known to have been carried out on facilities in temperate environments, and the presence and the preponderance of facilities in these environments around the world, a study into the observed benefits of mud-farming techniques in a temperate climate is warranted.

\subsection{Management of bauxite residue at Aughinish Alumina Ltd}

Aughinish Alumina Ltd (AAL) is an alumina refinery situated on Aughinish Island on the south side of the Shannon estuary, approximately 20 miles downstream of Limerick, Ireland. The refinery produces over $1.95 \mathrm{M}$ t of alumina annually using the Bayer process. The bauxite residue material is deposited within the Bauxite Residue Disposal Area (BRDA) as paste slurry at a moisture content $\left(m_{c}\right)$ of approximately $72 \%$ $\left(\mathrm{W}_{\mathrm{w}} / \mathrm{W}_{\mathrm{s}}\right)$. The deposited residue is relatively fine in nature, comprising of approximately $63 \%$ silt-sized particles and $30 \%$ clay-sized particles, with $50 \%$ of the material finer than $0.004 \mathrm{~mm}$.

Bauxite residue is currently disposed of within an approximately $1.8 \mathrm{M} \mathrm{m}^{2} \mathrm{BRDA}$, with deposition split between two phases (Figure 1). Phase 1 of the BRDA, which is the focus of this study, covers a total area of approximately $1 \mathrm{M} \mathrm{m}^{2}$. Phase 1 has been raised, in $2 \mathrm{~m}$ stages, to a maximum height of approximately $32 \mathrm{~m}$. Raising of the facility is carried out using a series of rockfill impoundment bunds constructed on an upstream basis directly on the bauxite residue. The ability of the facility to be raised is therefore dependent on the strength of the underlying bauxite residue. The site has a mean annual precipitation of $926.7 \mathrm{~mm}$, which is spread relatively evenly throughout the year, along with a mean maximum temperature of $13.5^{\circ} \mathrm{C}$ (The Irish Meteorological Service 2014).

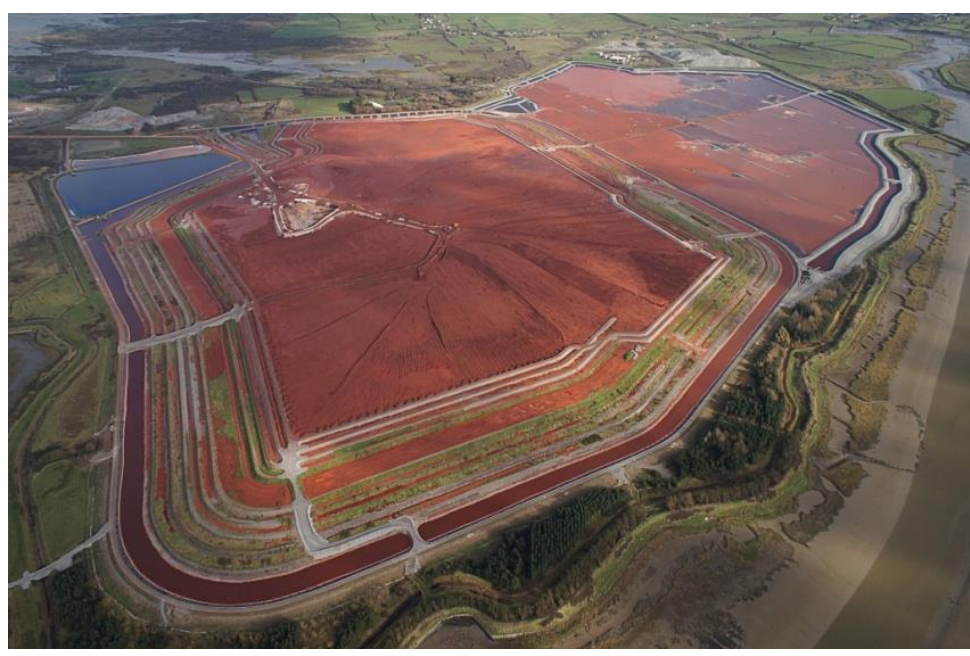

Figure 1 BRDA at AAL (Phase 1, which is the focus of this study, is shown on the left of the photo) 
Bauxite residue has been deposited within Phase 1 since 1983 and prior to 2009, the bauxite residue was deposited in relatively thick layers (around $1 \mathrm{~m}$ ) and allowed to consolidate under its own weight until conditions allowed for the placement of the next layer and the cycle repeated. This process led to moderate increases in both the density and undrained shear strength $\left(\mathrm{S}_{u}\right)$ of the residue. However, since 2009, AAL have carried out mud-farming to increase both the magnitude and rate of consolidation to enable the height of the facility to be increased safely as well as to maximise the area available for storage. The adopted mud-farming methods comprise of the deposition of thinner layers (approximately $600 \mathrm{~mm}$ ), followed by the use of an amphibious scrolling tractor (AST), commonly known as an amphirol (Figure 2). This AST comprises of a pair of hydraulically driven Archimedes screws, enabling access to very soft deposited residue much earlier than would be possible using conventional earth moving plant. These screws create ridges within the surface of the bauxite residue for increased evaporation and management of storm water. The action of the AST also provides mechanical consolidation of the bauxite residue.

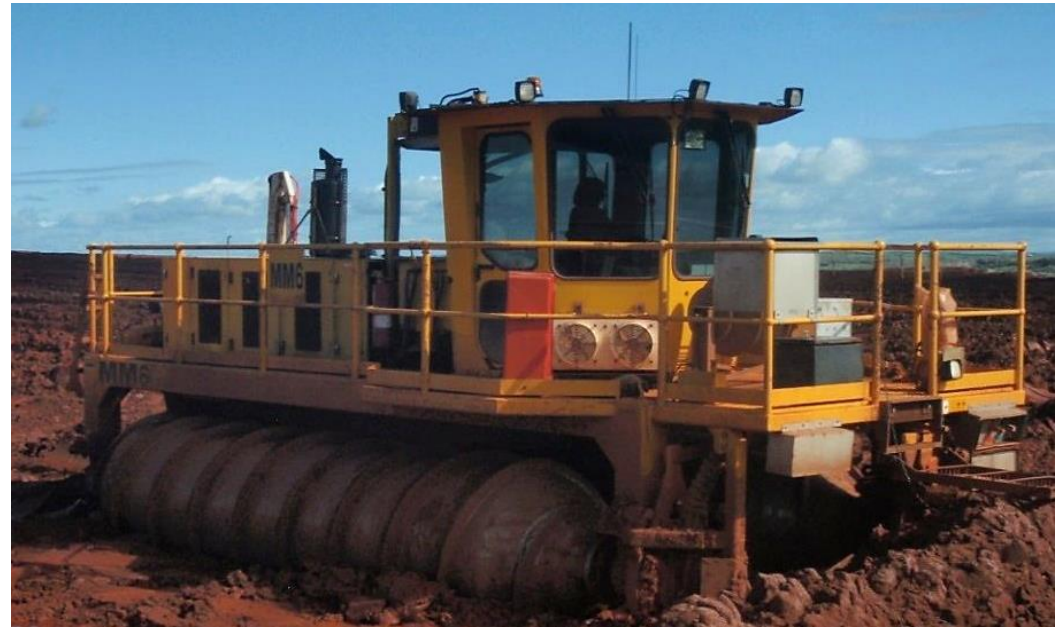

\section{Figure 2 AST utilised at AAL}

Based on the deposition history, mud-farming operations at the site, along with the availability of geotechnical data from previous ground investigations, the authors believe that the Aughinish BRDA presents an ideal opportunity to investigate the effectiveness of bauxite residue mud-farming in a temperate climate with the goal of determining the in situ density and shear strength obtained.

In addition, work by Sutar et al. (2014) showed that a certain proportion of the moisture content $\left(m_{c}\right)$ of bauxite residue samples is present within the structure of the solid particles. As this water does not form part of the 'free water' it does not affect the engineering behaviour of the samples and as such should not be considered when testing bauxite residue. The authors note that the possible effect of amorphous water content, water which is contained within the cryptocrystalline structure, on bauxite residue properties has not been discussed within the majority of recent research in the field. This study will therefore explore these effects.

The authors believe that this study will be of interest not only to operators of BRDAs in temperate climates but also to the wider mine tailings industry. This study aims to illustrate whether mud-farming presents a possible technique to reduce both mine water consumption and improve the stability of tailings facilities in temperate climates, which will ultimately lead to a more balanced solution from the triple baseline (economic, social, environmental) perspective.

\section{$2 \quad$ Methodology}

Work by others (Li \& Rutherford 1996; Cooling et al. 2002) has shown that the properties of bauxite residue are highly variable depending on both the origin of the bauxite ore as well as the processing methods utilised at individual facilities. Therefore, in order to avoid potential error as a result of varying ore and process conditions, data utilised within this study has been obtained from primary sources comprising of 
both historical site investigations as well as a new site investigation devised for this study, and carried out at the AAL BRDA in 2014.

\subsection{Historical site investigations}

Between 1983 and 2010, regular site investigations were carried out to track the performance of the non-farmed bauxite residue. Data from the last six site investigations (2002, 2004, 2005, 2007, 2009 and 2010) have been selected for use within this study. The data collected is principally comprised of the following:

Soil characterisation data including $m_{c}$, dry and bulk densities $\left(\gamma_{d}, \gamma_{b}\right)$, particle density $\left(\rho_{d}\right)$, specific gravity $\left(\mathrm{G}_{\mathrm{s}}\right)$ and Atterberg limits; and undrained shear strength obtained from Undrained Unconsolidated triaxial testing (UU), GEONOR in situ shear vane testing and laboratory Hand Shear Vane testing (HSV).

\section{$2.2 \quad 2014$ site investigation and testing programme}

In order to determine the properties and behaviours of the farmed materials and to fill gaps in the data obtained from the historical investigations, a new ground investigation was conducted in April 2014.

\subsubsection{Cone penetration testing}

A total of 24 cone penetration test with pore water pressure measurement (CPTu) profiles were carried out as part of the 2014 site investigation. These profiles were used to determine the strength profile of both farmed and non-farmed residues. CPTu testing was conducted on a limited area of the BRDA as dictated by current operations and areas which had been prepared for access by the test equipment.

CPTu testing was conducted using a $14 \mathrm{t}$ wide-tracked crawler rig, and was carried out using a calibrated CPTu cone to BS EN ISO 22476-1:2012 (British Standards Institution 2013).

Due to the soft silt nature of the bauxite residue, the obtained total cone resistance $\left(Q_{c}\right)$ values have been corrected to account for the effect of pore water pressure $(\mu)$ acting on the cone, as per Lunne et al. (1997), to calculate the corrected cone resistance $\left(Q_{t}\right)$. Values were then normalised against total vertical stress to obtain net cone resistance values $\left(Q_{\text {net }}\right)$.

\subsubsection{MOSTAP sampling}

In total 30, $1.5 \mathrm{~m}$ long MOSTAP samples of bauxite residue were recovered for laboratory testing. Of these samples 18 were recovered from farmed residue, whilst 12 were recovered from non-farmed residue.

These MOSTAP samples were recovered from holes immediately adjacent to the CPTu profile. In general, the distance between CPTu and MOSTAP was $<0.5 \mathrm{~m}$.

\subsubsection{Laboratory testing programme}

In order to determine geotechnical parameters relevant to this study, the 30 MOSTAP samples were subjected to geotechnical soils testing at a United Kingdom Accreditation Service (UKAS) accredited laboratory. All testing, with the exception of the Alcan particle density $\left(\rho_{d}\right)$ and modified $m_{c}$ testing were carried out in accordance with BS 1377 (British Standards Institution 1990). A summary of the laboratory testing carried out is provided below.

\subsubsection{Comparative moisture content testing}

Due to the possibility of amorphous water content within the bauxite residue, comparative $m_{c}$ in line with recommendations by Fourie (1997) was utilised. This testing was carried out in advance of the other testing so that the results could be incorporated into future testing procedures.

Testing was carried out on two samples per test, removed from approximately the same depth from within the same MOSTAP sample. These samples were then prepared as per normal $m_{c}$ testing but with the two 
samples being dried at 50 and $110^{\circ} \mathrm{C}$ respectively. A comparison of the moisture contents determined at the two drying rates showed that drying at $110^{\circ} \mathrm{C}$ produced an $\mathrm{m}_{\mathrm{c}}$ that is on average $1.3 \%$ higher than drying at $50^{\circ} \mathrm{C}$ due to the fact that the bound anhydrous water was evaporated at the higher temperature. Based on the results of drying at different temperatures (see Section 3.2 below), all subsequent testing, which involved the drying of samples, was carried out at a drying temperature of $50^{\circ} \mathrm{C}$.

As a result of the comparative $m_{c}$ testing, it was necessary to modify many of the test results carried out on residue samples prior to 2014. In the case of $\mathrm{m}_{\mathrm{c}}$ testing, values obtained prior to 2014 have been modified by $-1.3 \%$, based on the average difference in $m_{c}$ observed. Using the corrected $m_{c}$ and $\gamma_{b}$ testing, which does not require drying of the material, the $\gamma_{d}$ values were recalculated as per the method suggested by BS 1377:1990, Part 2.

\subsubsection{Soil characterisation testing}

Soil characterisation testing was carried out to determine the properties of farmed bauxite residue as well as to fill the gaps left by the exclusion of earlier data. Testing comprised of $m_{c}, \gamma_{d}, \gamma_{b}$ and Atterberg limit testing. Due to the results of the comparative $m_{c}$ testing, subsequent testing for $m_{c}$ and $\gamma_{d}$ were carried out at drying temperatures of $50^{\circ} \mathrm{C}$. In addition, $\mathrm{m}_{\mathrm{c}}$ testing within the farmed materials was specified at target depths to correspond to the peaks and troughs observed in the CPTu testing.

\subsubsection{Particle density testing}

$\rho_{\mathrm{d}}$ testing in the UK has traditionally been carried out to BS 1377, Part 2 (British Standards Institution 1990). This method requires that the sample passes a $2 \mathrm{~mm}$ sieve. Therefore, it has been common practice within the Alumina industry to adopt the Aluminium Laboratories Ltd method 305-61 (n.d.), often referred to as the Alcan Method. This method requires that material passes the US \#200 mesh $(0.074 \mathrm{~mm})$. As a result, anecdotal evidence suggests that the Alcan method provides a better determination of $\rho_{d}$, than BS 1377 (British Standards Institution 1990), when applied to bauxite residue. As a result, the Alcan Method was used within this study. Tests were modified so that drying of the samples was carried out at $50^{\circ} \mathrm{C}$, in accordance with the results of the comparative $m_{c}$ testing.

\subsubsection{Undrained shear strength testing}

$\mathrm{S}_{\mathrm{u}}$ testing was carried out using $38 \mathrm{~mm}$ diameter, single stage, $\mathrm{UU}$ tests. Each test was carried out as a set of three samples with increasing cell pressures. Cell pressures were determined based on the value of $\gamma_{b}$ from soil characterisation testing and the depth of the sample, averaged over the recovered $1.5 \mathrm{~m}$ MOSTAP length. A minimum cell pressure of $50 \mathrm{kPa}$ was specified to prevent testing procedure errors. Cell pressures ranged from $50-600 \mathrm{kPa}$.

Long (2007) shows that interpretation of undrained shear strengths for UU tests carried out for inorganic estuarine silts can be problematic due to sample disturbance and the potential for negative pore water pressures to develop during shearing, both of which can cause overestimations of a silt sample's true in situ strength. As a result, all UU tests were carried out with stress-strain relationship measurements. Testing was continued until failure or a strain of approximately $20 \%$ was achieved.

\section{$3 \quad$ Results}

\subsection{Cone penetration testing}

Figure 3 presents the results of the CPTu testing carried out as part of the 2014 site investigation works. In general, it can be seen that the residue within the top $5 \mathrm{~m}$ has higher $\mathrm{Q}_{\text {net }}$ values than the residue below. A number of high responses were also recorded at depths of approximately 7.5, 11 and $17 \mathrm{~m}$ respectively. Data from the CPTu testing indicates that these layers are likely to be representative of layers of process sand, which are generally separated prior to deposition in the BRDA but have been deposited in the past, and as such are not considered representative of the overall bauxite residue. 
In general, net cone resistance values within the top $5 \mathrm{~m}$ appear reasonably constant with depth. Values in the general range of between 1,000 and $4,000 \mathrm{kPa}$ were recorded, although values as high as $15,000 \mathrm{kPa}$ and as low as $200 \mathrm{kPa}$ were also observed.

Within the residue below $5 \mathrm{~m}$ there is a broad trend for the cone resistance values to increase with depth. In general, values increase from approximately $600 \mathrm{kPa}$ at a depth of $5 \mathrm{~m}$ to $1,000 \mathrm{kPa}$ at a depth of $27.5 \mathrm{~m}$. With the exclusion of the values recorded for the sand layers, a range of values between 40-3,000 kPa were recorded.

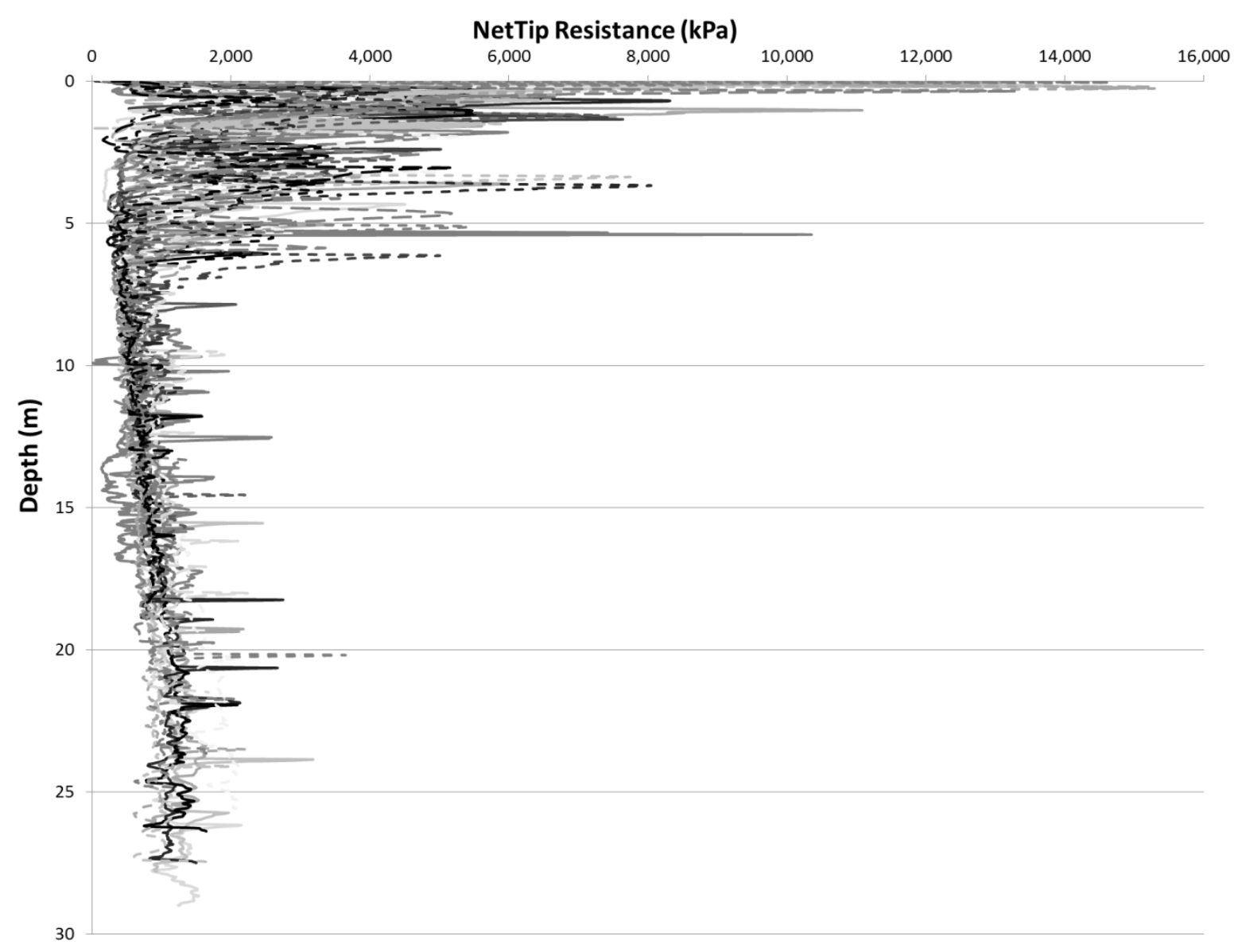

Figure 3 CPTu test results from 2014 site investigation at AAL

\subsection{Comparative moisture content testing}

In general, the results indicate that drying at $110^{\circ} \mathrm{C}$ leads to the calculation of higher $\mathrm{m}_{\mathrm{c}}$ than for samples subjected to drying at $50^{\circ} \mathrm{C}$. The difference in $\mathrm{m}_{\mathrm{c}}$ for tests carried out on the same sample ranged from between 0 and $3 \%$, with an average of $1.3 \%$. In total, $92 \%$ of the data showed a difference in $m_{c}$ of equal to or greater than $1 \%$ and approximately $32 \%$ of the data showed a difference of greater than $1 \%$.

\subsection{Moisture content testing}

The $\mathrm{m}_{\mathrm{c}}$ determined at a drying temperature of $50^{\circ} \mathrm{C}$ within the farmed residue ranged from between $26-38 \%$, whilst the values within the non-farmed residue ranged from between 31 and $49 \%$. In both data sets there does not appear to be any relationship between $\mathrm{m}_{\mathrm{c}}$ and depth.

\subsection{Bulk and dry density}

In general, $\gamma_{b}$ within the farmed residue ranged from between $21.5-24.5 \mathrm{kN} / \mathrm{m}^{3}$, with a mean value of $22.5 \mathrm{kN} / \mathrm{m}^{3}$. Within non-farmed residue, $\gamma_{b}$ ranged from between $15.3-24.5 \mathrm{kN} / \mathrm{m}^{3}$, with a mean value of $21.5 \mathrm{kN} / \mathrm{m}^{3}$. 
In general, $\gamma_{d}$ within the farmed residue ranged from between $15.6-18.5 \mathrm{kN} / \mathrm{m}^{3}$, with a mean value of $16.8 \mathrm{kN} / \mathrm{m}^{3}$, whilst within non-farmed residue $\gamma_{\mathrm{d}}$ ranged from between $14.3-17.9 \mathrm{kN} / \mathrm{m}^{3}$, with a mean value of $15.5 \mathrm{kN} / \mathrm{m}^{3}$.

\subsection{Undrained shear strength}

$\mathrm{S}_{\mathrm{u}}$ values were determined using UU testing, GEONOR in situ shear vane testing and laboratory conducted HSV testing. To enable analyses of the potential for sample disturbance $S_{u}$ values from triaxial testing have been taken at the peak strain as well as at strains of 1 and $2 \%$.

Figure 4 presents the results of $\mathrm{S}_{u}$ testing against depth for each of the testing methods as well as identifying variations in farmed and non-farmed residue.

In general, the triaxial data presents a link between $\mathrm{S}_{\mathrm{u}}$ and the adopted strain with the largest $\mathrm{S}_{\mathrm{u}}$ values being achieved at peak strains (between approximately 23 and $300 \mathrm{kPa}$ ), followed by the values at $2 \%$ strain (between approximately 3 and $29 \mathrm{kPa}$ ) and finally values at $1 \%$ strain (between approximately 1 and $39 \mathrm{kPa}$ ). In addition, the $\mathrm{S}_{\mathrm{u}}$ values obtained for farmed residue were generally higher than those for the non-farmed residue. For values taken at peak strain, mud-farmed values of between approximately 37 and $300 \mathrm{kPa}$ were obtained, compared to values between approximately 23 and $127 \mathrm{kPa}$ in the non-farmed residue. For values taken at $2 \%$ strain, mud-farmed values of between approximately 3 and $129 \mathrm{kPa}$ were obtained, compared to values between approximately 3 and $65 \mathrm{kPa}$ in the non-farmed residue. For values taken at $1 \%$ strain mud-farmed values of between approximately 3 and $39 \mathrm{kPa}$ were obtained compared to values between approximately 1 and $28 \mathrm{kPa}$ in the non-farmed residue.

On average it was seen that the values obtained by Laboratory HSV and in situ vane testing, conducted historically in non-farmed residue, were similar. Values between 1.8 and $63 \mathrm{kPa}$ were achieved using the in situ GEONOR vane and values between 0.4 and $58 \mathrm{kPa}$, for laboratory HSV testing. 


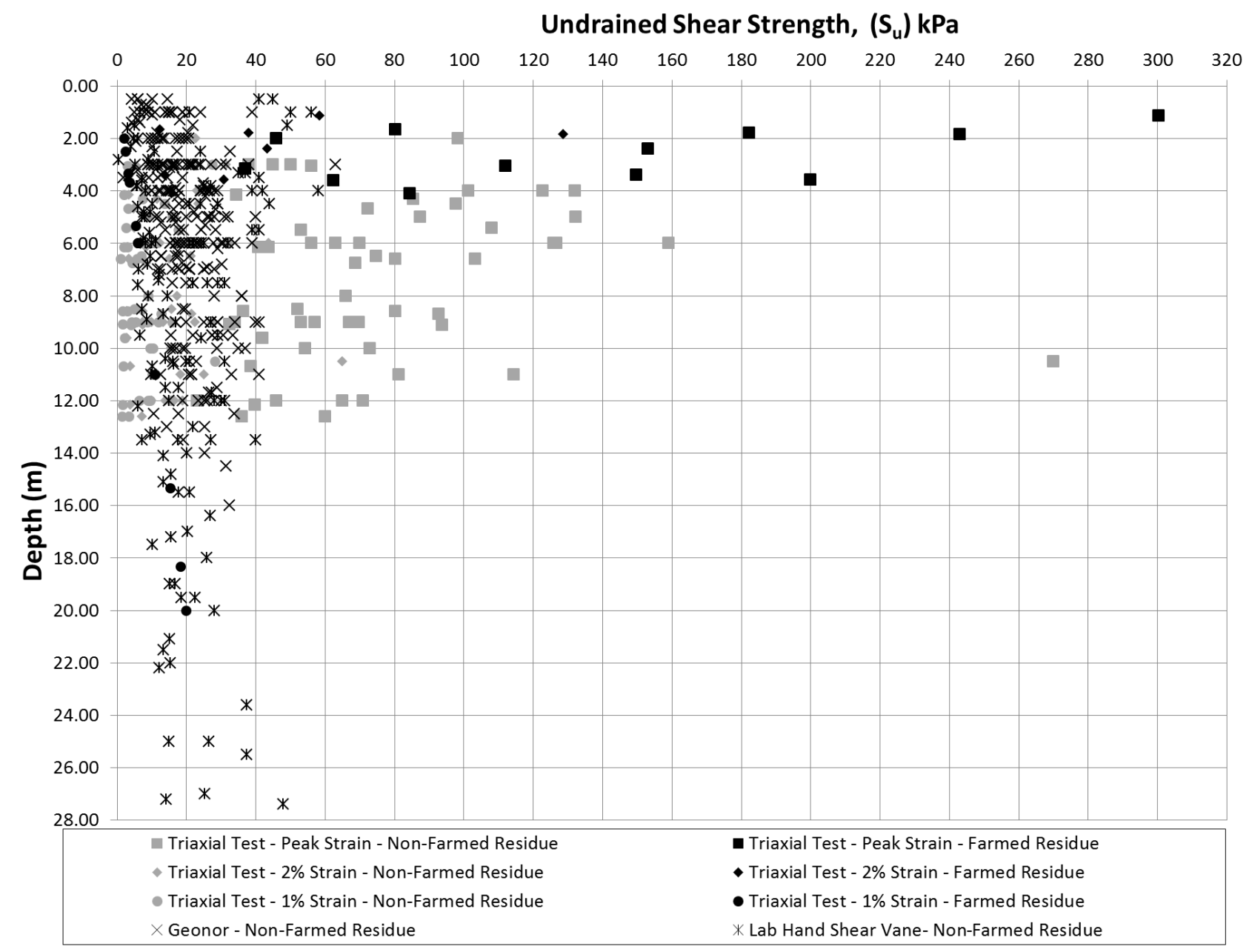

Figure 4 Undrained shear strength against depth for triaxial testing (peak, 1 and $2 \%$ strain), GEONOR testing and HSV testing

\section{$4 \quad$ Analysis}

\subsection{Observed behaviour in bauxite residue from CPTu}

The results of CPTu testing indicate a variation in the behaviour of the residue located in the top $5 \mathrm{~m}$ and those located below this depth. When comparisons are made between site surveys carried out prior to and during mud-farming operations, a general farmed depth between 4 and $6 \mathrm{~m}$ is observed. Therefore, the results demonstrate that the variations observed in the top $5 \mathrm{~m}$ of the CPTu data are likely to be representative of the behaviour of farmed residue, whilst the results below this depth are likely to be representative of the behaviour of non-farmed residue.

Within the non-farmed residue there is a general trend for the cone resistance to increase with depth. On average, the relationship between net cone resistance and depth $\left(Q_{\text {net }} /\right.$ depth) can be shown to be $17 \mathrm{kPa} / \mathrm{m}$ (Figure 5). These results demonstrate that the densification and strength gain of non-farmed residue at AAL is highly dependent on the overburden generated by the deposition of additional residue. Based on an annual deposition of $0.78 \mathrm{M} \mathrm{m}^{3}$ of bauxite residue $\left(1.2 \mathrm{Mt}\right.$ at an average $\gamma_{d}$ of $\left.1.55 \mathrm{Mg} / \mathrm{m}^{3}\right)$ on the $1 \mathrm{M} \mathrm{m}^{2}$ BRDA Phase 1, it can be expected that $Q_{\text {net }}$ values within non-farmed, self-consolidating, residue will increase by approximately $13 \mathrm{kPa}$ per year. 


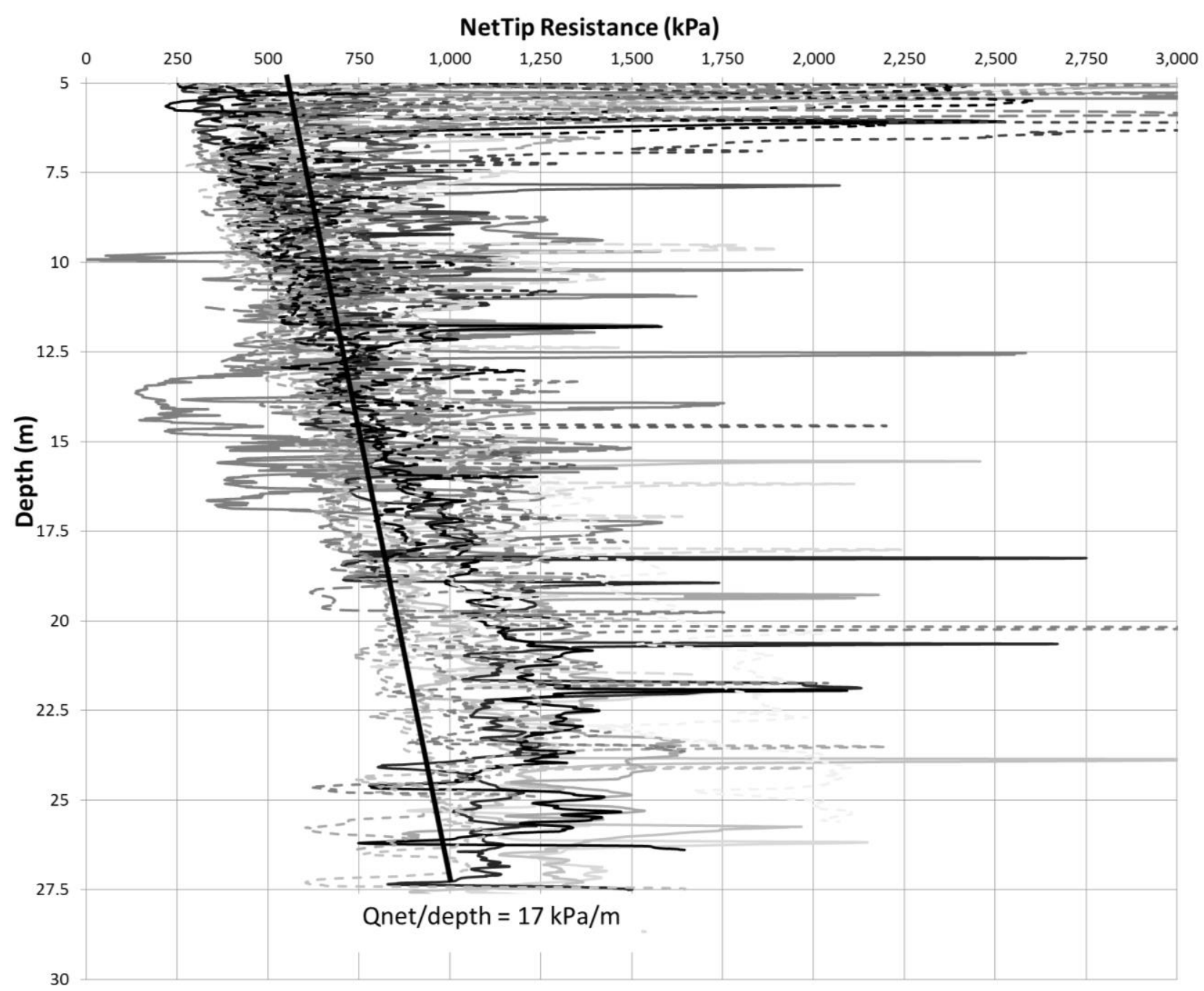

Figure 5 Average $\mathrm{Q}_{\text {net }}$ with depth for non-farmed residue

CPTu testing indicates that, in general, the behaviour of the farmed residue is unaffected by depth, with very little additional increase in $Q_{\text {net }}$ values occurring as a result of increased effective stress $\left(\sigma_{v}^{\prime}\right)$. Farmed residue had a general range of $Q_{\text {net }}$ values of between 1,000 and $4,000 \mathrm{kPa}$, with an average of approximately $2,000 \mathrm{kPa}$ (Figure 6). These values appear consistent with the work carried out by Li et al. (2011) on farmed residue in Western Australia, where CPT values of between 1,500 and 5,000 kPa, with an average of 2,500 kPa, were recorded. However, in similar results to those obtained by Li et al. (2011), there appeared to be significant layering of the farmed residue with $Q_{\text {net }}$ values varying between 200 and $15,000 \mathrm{kPa}$. As with the results of Li et al. (2011), this was not observed to the same extent within the non-farmed residue, which showed a narrower range of $Q_{\text {net }}$ values ( 40 and 3,000 kPa). In general it can be seen that the peaks and troughs in $Q_{\text {net }}$ values within the farmed residue vary in distance between 0.5 and $1 \mathrm{~m}$. This appears to correlate with information from AAL regarding the range of thicknesses for the individually farmed residue layers. These are likely to of been deposited at varying process conditions and affected by different climate conditions prior to the deposition of additional layers which may cause, for example, desiccated layers of farmed residue or ponded water to be trapped. These hypotheses appear to be supported by a comparison of $m_{c}$ against these peaks and troughs which indicate significant variations in $\mathrm{m}_{\mathrm{c}}$.

Analyses also indicate that lower $\mu$ values are present within the farmed residue, generally increasing from approximately $0 \mathrm{kPa}$ at the surface to $200 \mathrm{kPa}$ at a depth of $5 \mathrm{~m}$, than in the non-farmed residue where values in excess of $1,000 \mathrm{kPa}$ were recorded. This suggests that the increase in $Q_{\text {net }}$ values within the farmed residue is likely to be a result of the removal of water and consolidation achieved by the use of 
amphirols at the site. In addition, analyses show that for non-farmed residue the $Q_{\text {net }}$ value increases as the $\mu$ increases. This suggests that $\mu$ within the non-farmed residue are unable to dissipate, even over many years.

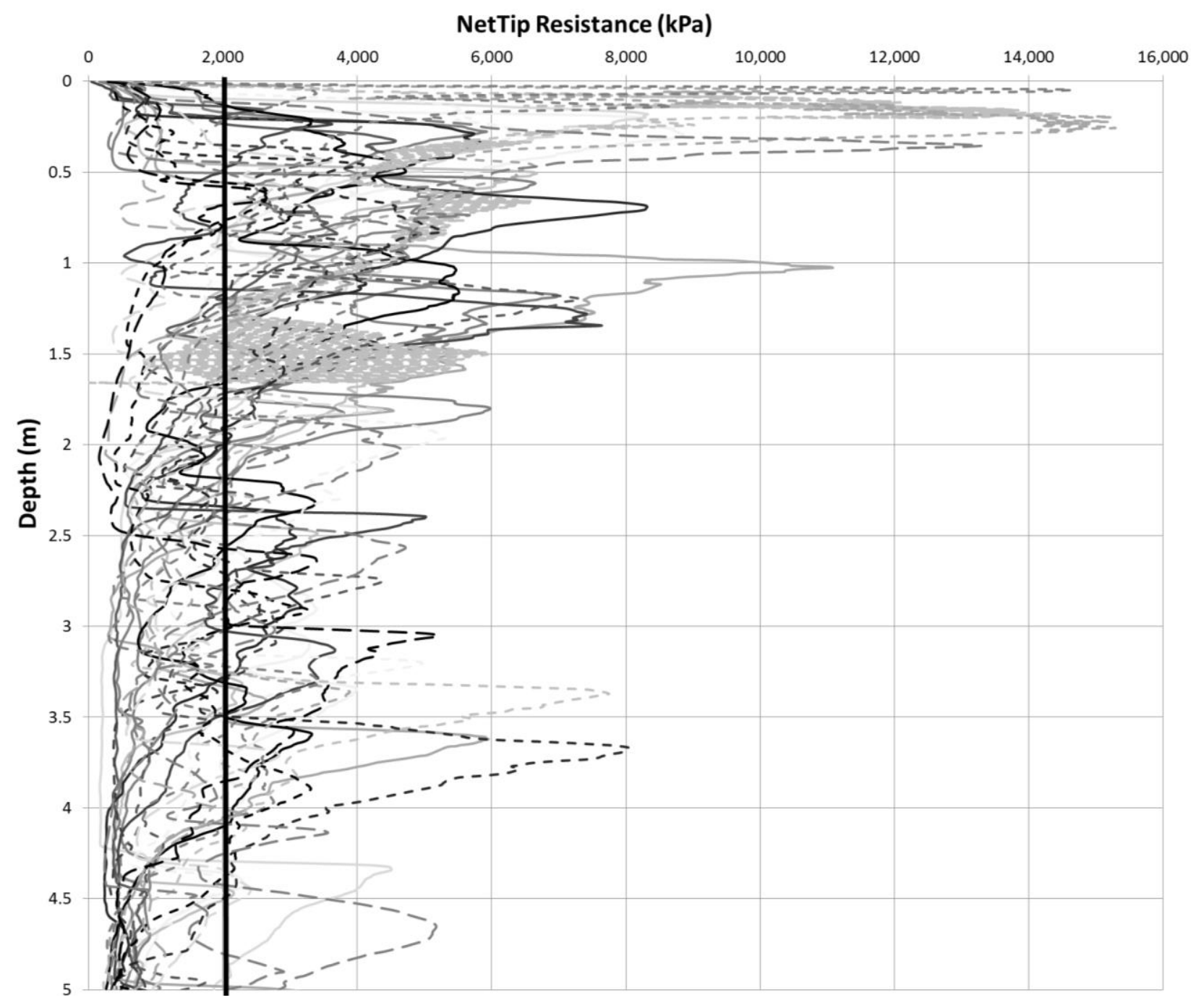

Figure 6 Average $Q_{\text {net }}$ with depth for farmed residue

\subsection{Amorphous water content of bauxite residue}

Based on the results of the comparative $m_{c}$ testing, it is apparent that the bauxite residue at AAL contains up to $3 \%$ water which is contained within the cryptocrystalline structure. As this moisture does not form part of the 'free water', and cannot be lost during normal consolidation, it should not be considered when deriving geotechnical properties.

Based on conventional soil mechanics theory it can be seen that, for a fully saturated soil, the specific gravity of soil solids $\left(G_{s}\right)$, which contains any amorphous water, is dependent on the calculation of the free $m_{c}$. In addition, the calculation of $\gamma_{d}$ is dependent on the value of $G_{s}$. In order to quantify the level of error that can be caused by a miscalculation of the $m_{c}$, as a result of drying at $110^{\circ} \mathrm{C}$, values of both $\mathrm{G}_{\mathrm{s}}$ and $\gamma_{\mathrm{d}}$ have been calculated, based on saturated soil theory. These were calculated at a range of void ratios $(e)$ between 0.75 and 1.25 , and based on $m_{c}$ at $110^{\circ} \mathrm{C}$ of $32 \%$. Both the average (1.3\%) and maximum (3\%) observed differences in the $\mathrm{m}_{\mathrm{c}}$ from the comparative testing were considered.

Analysis indicates that, for the average $m_{c}$ difference, the miscalculation in $G_{s}$ and $\gamma_{d}$ is approximately $4 \%$, whilst the for the maximum $m_{c}$ difference, the miscalculation in $G_{s}$ and $\gamma_{d}$ is approximately $10 \%$. The difference is slightly higher at higher void ratios but is not considered significant over the range considered. 


\subsection{Density}

Testing indicates that, on average, farmed residue has a higher $\gamma_{d}\left(16.8 \mathrm{kN} / \mathrm{m}^{3}\right)$ than non-farmed residue $\left(15.5 \mathrm{kN} / \mathrm{m}^{3}\right)$. This represents an $8.4 \%$ increase in density as a result of mud-farming.

\subsection{Undrained shear strength}

The results of the $S_{u}$ testing, shown in Figure 4, appear to indicate large variations in the values obtained using different techniques. However, this relationship does not take account of potential variations in the $\mathrm{m}_{\mathrm{c}}$ of the samples, which have been shown to have a significant impact on the $\mathrm{S}_{\mathrm{u}}$ of bauxite residue.

Based on an analysis for the plot of $S_{u}$ against $m_{c}$ for GEONOR vane testing, laboratory shear vane testing and UU testing, at peak, 2 and $1 \%$ strain it was seen that a similar relationship to that obtained for $\mathrm{S}_{\mathrm{u}}$ against depth was obtained, with values taken at peak strain from UU testing given the highest values of $\mathrm{S}_{\mathrm{u}}$ and $1 \%$ strain values from UU testing giving the lowest. The laboratory testing of mine silt tailings is particularly difficult due to sample disturbance. This often causes materials to densify prior to testing and, as a result, there is a tendency to overestimate $S_{u}$. Therefore, it is not believed that the results from either the peak strain UU or laboratory HSV testing are representative of the in situ behaviour and as such are excluded in the establishment of site-specific correlations as part of this study. Upon examination of the values obtained at $1 \%$ strain from the UU testing, it can be seen that the values range between 1 and $34 \mathrm{kPa}$ with an average of $8 \mathrm{kPa}$. Based on the high $\mathrm{Q}_{\text {net }}$ values obtained from CPTu testing, as well as excessive deflection caused in the rods whilst attempting GEONOR vane testing in 2014, these values are also not believed to be representative of the in situ behaviour. When values obtained from the GEONOR vane testing and at $2 \%$ strain from the UU testing are compared, a reasonably close correlation between the two data sets was observed (Figure 7).

An attempt was made to correlate cone resistance values with $S_{u}$ using three empirical cone factors presented by Lunne et al. (1997), empirical total cone factor $\left(N_{k}\right)$, empirical effective cone factor $\left(N_{k e}\right)$ and empirical pore water pressure cone factor $\left(N_{\Delta \mu}\right)$. These analyses were carried out by cross referencing values of $Q_{n e t}$ and $\mu$ from the CPTu data with the adopted values of $S_{u}$, determined from UU triaxial and shear vane testing to determine whether any correlations exist for which reasonable confidence could be derived. Calculations indicated large variations in the values determined for all three of the empirical cone factors, which were derived based on performance in clays. As such, it is not believed that any of the three correlations are applicable to predominately silt bauxite residue, and as such cannot be used with any level of confidence. Given the relationship between $S_{u}$ and $m_{c}$ for bauxite residue, the authors believe that a correlation between $Q_{n e t}$ and $S_{u}$ may exist based on a normalisation with $m_{c}$, although this has not been explored further in this study.

Based on the data analysed and the difficulties encountered, the authors believe that, in this instance, the adoption of $\mathrm{S}_{\mathrm{u}}$ values obtained from GEONOR vane testing as well as at $2 \%$ strain from the UU testing provides the best data set with which to derive site-specific correlations and as such the data obtained from the other methods is not considered further in this study.

The adoption of $S_{u}$ values at $2 \%$ is consistent with the method suggested by Long (2007). However, it is noted that this approach requires further validation. Furthermore, the authors recognise the difficulties associated with the use of shear vane testing due to disturbance of the soil to be tested. In addition, their use in silt materials is problematic due to the tendency of silts to drain during shear causing the silt to enter a partially saturated state which prevents the true $S_{u}$ from being measured. 


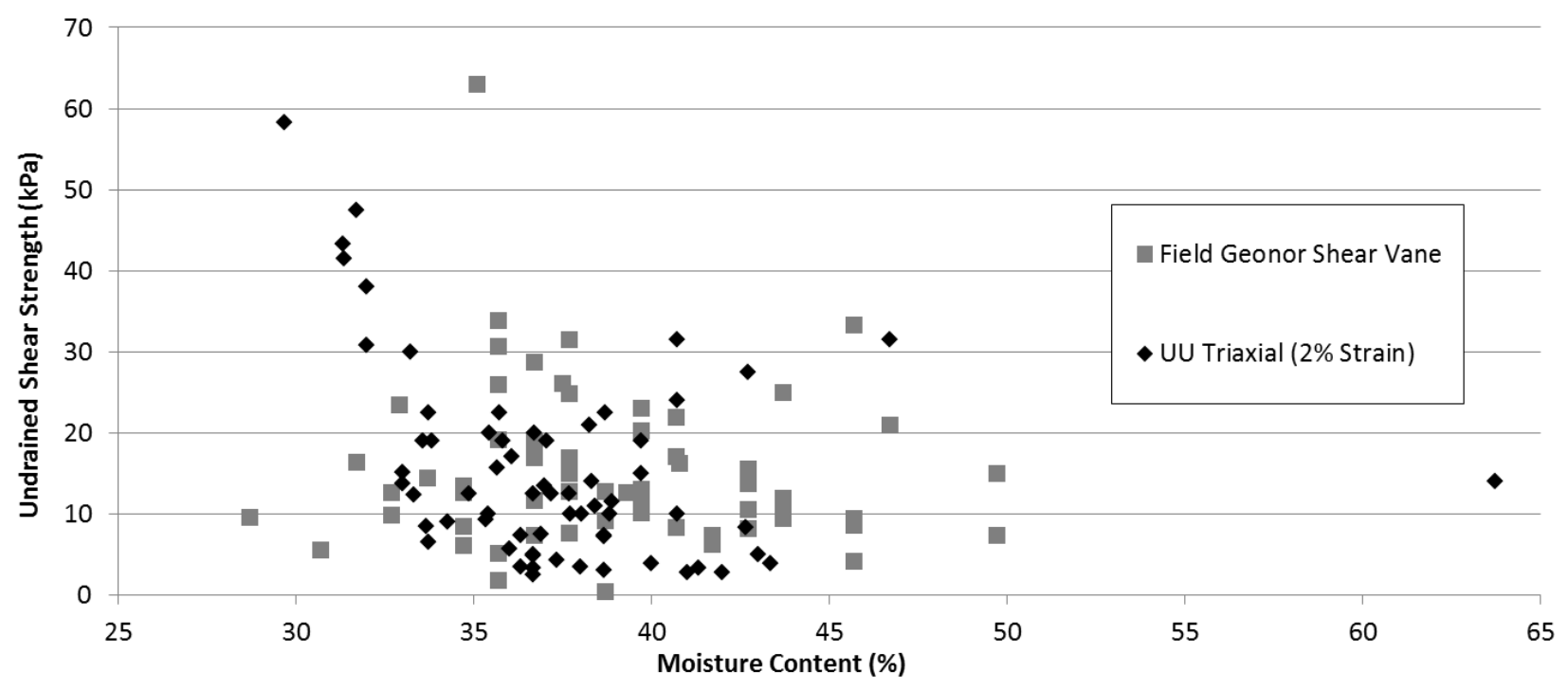

Figure 7 Relationship between undrained shear strength ( $2 \%$ strain and GEONOR) against moisture content

\subsection{Site-specific correlation between undrained shear strength and overburden}

It has been shown that for wet-deposited, non-farmed, residue there appears to be an increase in strength with depth (Figure 5). In order to explore the strength gain of the non-farmed residue more fully, the $S_{u}$ has been plotted against $\sigma^{\prime}$ (Figure 8). Based on the data presented an undrained shear strength to effective vertical stress ratio $\left(\mathrm{S}_{\mathrm{u}} / \sigma_{\mathrm{v}}{ }_{\mathrm{v}}\right)$ of 0.08 has been adopted.

Based on the deposition of approximately $0.78 \mathrm{~m}$ of residue per year, on the Phase 1 area, at a $\gamma_{d}$ of $15.5 \mathrm{kN} / \mathrm{m}^{3}$, it can be calculated that the strength of non-farmed residue will increase by approximately $0.97 \mathrm{kPa}$ per annum. Therefore, the range of $\sigma^{\prime}$ v presented in Figure 8 represents a time period of approximately 21 years.

It is acknowledged that there is significant scatter in the results and as such that the correlation factor will be low. However, given the potential for residue variations (moisture content at deposition, specific gravity, climatic conditions whilst exposed and bauxite origin) this is not surprising. It can be seen, however, that the majority of the data presented possesses an undrained shear strength between 5 and $20 \mathrm{kPa}$ at an effective overburden pressure of between 50 and $200 \mathrm{KPa}$. And as such the correlation adopted is believed to be a reasonable approximation of the relationship for unfarmed residue undergoing self-weight consolidation. 


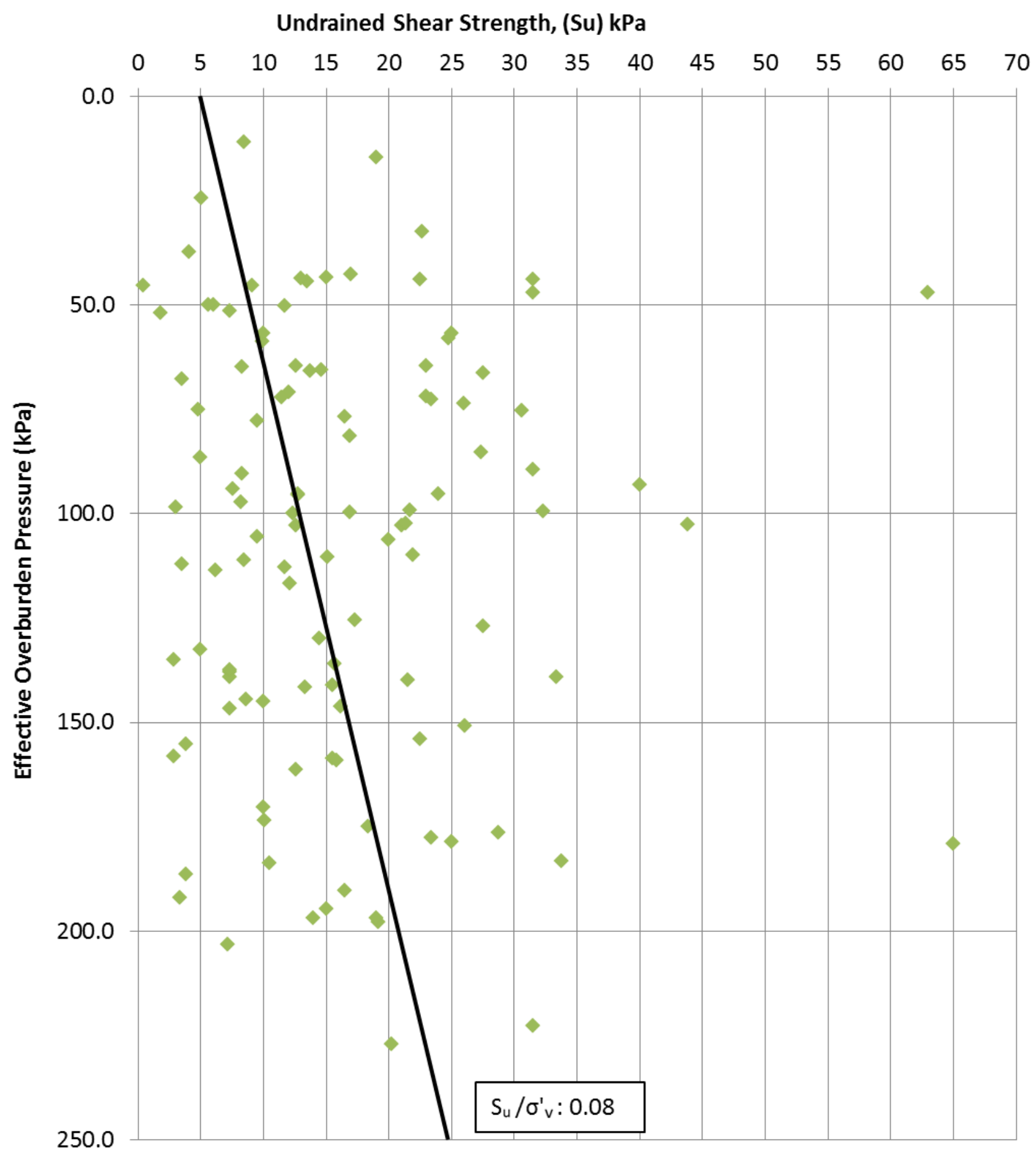

Figure 8 Derived site-specific correlations between undrained shear strength (from triaxial testing at $2 \%$ strain and GEONOR) and effective overburden

\subsection{Site-specific correlation between undrained shear strength and moisture content}

Based on the analyses carried out as part of this study, site-specific correlations between $S_{u}$ and $m_{c}$ (from drying at $50^{\circ} \mathrm{C}$ ) has been derived for both farmed and non-farmed residue and are presented in Figure 9. 


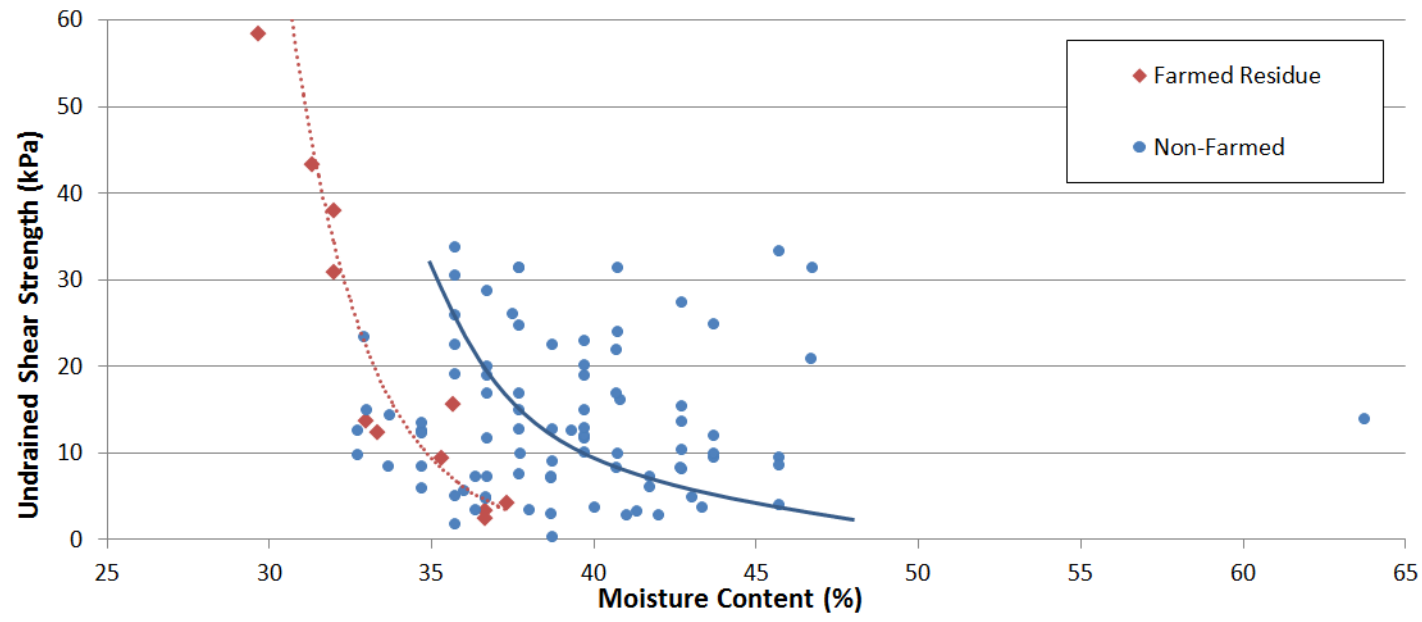

Figure 9 Derived site-specific correlations between undrained shear strength (from triaxial testing at $\mathbf{2 \%}$ strain and GEONOR) and moisture content for farmed and non -farmed residue

The correlations between $S_{u}$ and $m_{c}$ shown in Figure 9 show that in general the correlation for farmed residue sits to the left of that for non-farmed residue indicating that in general the farmed residue has a lower moisture content and higher strength.

Based on the $S_{u} / \sigma^{\prime} v$ relationship established in Figure 8, an adopted boundary between farmed and non-farmed residue could be established at between 25 and $30 \mathrm{kPa}$. Farmed residue can be seen to possess $S_{u}$ values up to approximately $60 \mathrm{kPa}$. This represents a significant increase in $S_{u}$ as a result of mud-farming. In addition, it is also noted that the mud-farmed residues were deposited after the non-farmed residue (mud-farmed residues are up to approximately five years versus approximately 31 years for non-farmed residue).

\section{Conclusions}

The current study showed that the use of mud-farming at AAL led to an average increase of $8.4 \%$ in $\gamma_{d}$, from $15.5-16.8 \mathrm{kN} / \mathrm{m}^{3}$, of the bauxite residue. Based on a current deposition volume of $1.2 \mathrm{M} \mathrm{t}$ per year at AAL, this increase in $\gamma_{d}$ equates to the storage of an additional $60,000 \mathrm{~m}^{3}$ of bauxite residue within a given area.

Based on the general range of undrained shear strength and effective overburden pressures it has been shown that $S_{u}$ values of the non-farmed residue increase with $\sigma_{v}^{\prime}$, with $S_{u}$ values ranging from between approximately $5 \mathrm{kPa}$ at surface to $25 \mathrm{kPa}$ at an $\sigma^{\prime}{ }_{v}$ of $250 \mathrm{kPa}$. This is supported by the results of the CPTu testing (Figure 5) which indicated a $Q_{n e t} /$ depth ratio of $17 \mathrm{kPa} / \mathrm{m}$. Based on the data an undrained shear strength with effective vertical stress $\left(S_{u} / \sigma_{v}^{\prime}\right)$ ratio of 0.08 has been adopted. This equates to an annual strength gain of approximately $0.97 \mathrm{kPa}$, which indicates that it may take up to 21 years for self-consolidating residue to reach the $25 \mathrm{kPa} \mathrm{S}$ values determined by this study. It can therefore be concluded that self-weight consolidating residue are unlikely to provide the optimal storage solution at AAL.

The site-specific correlations presented as part of this study indicate that farmed residue, generally, possesses $\mathrm{S}_{\mathrm{u}}$ values in excess of those of non-farmed residues. Adopting an upper strength boundary of $30 \mathrm{kPa}$ for non-farmed residue and an upper boundary for farmed residue of $60 \mathrm{kPa}$. It can be determined that the farming of bauxite residue at AAL could achieve increases in $\mathrm{S}_{u}$ of up to $140 \%$. In addition, based on the deposition history at AAL it can be concluded that mud-farming enables higher undrained shear strengths to be achieved in a shorter period of time than can be achieved by self-weight consolidating non-farmed residue.

Based on the evidence presented it can be concluded that mud-farming operations at AAL have led to higher undrained shear strengths, lower moisture contents and higher densities and that this has been 
achieved despite the temperate climate of the site (mean annual precipitation of $926.7 \mathrm{~mm}$ and mean maximum temperature of $13.5^{\circ} \mathrm{C}$ (The Irish Meteorological Service 2014)).

This study has also demonstrated that there is a potential for bauxite residue to contain varying degrees of intra crystalline water, up to $3 \%$. It has also been discussed that this amorphous water can be removed at a temperature of $110^{\circ} \mathrm{C}$. An examination of the potential effect that the removal of this water can have on the calculated engineering properties reveals that, for a 3\% amorphous water content, the underestimation of $\gamma_{d}$ and $G_{s}$ is approximately $10 \%$.

Significant variations in values of $S_{u}$ have been shown to exist depending on the testing method used (triaxial testing and HSV) and the adopted limiting strain rate (peak, 1 and 2\%). In particular it has been demonstrated that the conventional adoption of strengths at peak strains in laboratory conducted triaxial strength testing has a tendency to overestimate strength and should be avoided. It is suggested that a limiting strain value be adopted based on either site-specific data or knowledge or, in absence of such data, a value of $2 \%$, as suggested by Long (2007). In addition, the findings suggest that the use of standard geotechnical testing oven drying temperatures (around $110^{\circ} \mathrm{C}$ ) should be avoided when applied to bauxite residue to prevent the potential for removal of intra crystalline water and hence miscalculations in $m_{c}$ and $\gamma_{d}$. The authors suggest that drying temperatures of $50^{\circ} \mathrm{C}$ should be used although additional studies at a range of drying temperatures would be beneficial.

\section{Acknowledgement}

The authors thank Tom Hartney and Ed Lowe, of Rusal Aughinish Alumina Ltd, primarily for the opportunity to carry out this study but also for the thought provoking conversations, guidance and insight into the alumina industry. Without them, this study would not have been possible.

\section{References}

Aluminium Laboratories Ltd n.d., Standard Method 305-61: Determination of real density or specific gravity of powdered materials: pycnometer procedure, Aluminium Laboratories Ltd, Arvida.

Australian Government Bureau of Meteorology 2014, Climate statistics for Australian locations, Perth regional office 1881 to 2010 , Australian Government Bureau of Meteorology, Melbourne, viewed 22 May 2014, http://www.bom.gov.au/climate/ averages/tables/cw_009034_All.shtml

British Standards Institution 1990, BS 1377: Methods of test for soils for civil engineering purposes, British Standards Institution, London.

British Standards Institution 1990, BS 1377-2 Part 2, Section 3: Determination of Moisture Content, British Standards Institution, London.

British Standards Institution 2013, BS EN ISO 22476-1:2012: Geotechnical investigation and testing - Field testing - Part 1: Electrical cone and piezocone penetration test, British Standards Institution, London.

Cooling, DJ, Hay, PS \& Guilfoyle, L 2002, 'Carbonation of bauxite residue', in S Chandrashekar (ed.), Proceedings of the 6th International Alumina Quality Workshop, AQW Inc., Perth, pp. 185-190.

Fourie, AB 1997, 'Classification and index tests', in GE Blight (ed.), Mechanics of residual soils, A.A.Balkema, Rotterdam.

$\mathrm{Li}, \mathrm{H}$, Pedrosa, S \& Canfell, A 2011, 'Case study - bauxite residue management at Rio Alcan Gove, Northern Territory, Australia ${ }^{\odot}$ ', in RJ Jewell \& AB Fourie (eds), Proceedings of the 14th International Seminar on Paste and Thickened Tailings, Australian Centre for Geomechanics, Perth, pp. 203-212.

Li, LY \& Rutherford, GK 1996, 'Effect of bauxite properties on the settling of red mud', International Journal of Mineral Processing, vol. 48, pp. 169-182.

Long, M 2007, 'Engineering characterization of estuarine silts', Quarterly Journal of Engineering Geology \& Hydrogeology, vol. 40, pp. 147-161.

Lunne, T, Robertson, PK \& Powell, JJM 1997, Cone penetration testing in geotechnical practice, E \& FN Spon, Oxon, UK.

Munro, LD \& Smirk, DD 2012, 'Optimising bauxite residue deliquoring and consolidation', in S. Rosenberg (ed.), Proceedings of the 9th Alumina Quality Workshop, AQW Inc., Perth, pp. 269-275.

Smirk, DD and Jackson, S 2010, 'In situ foundation improvement for upstream raising of embankments using dried tailings', in AB Fourie \& RJ Jewell (eds), Proceedings of the First International Seminar on the Reduction of Risk in the Management of Tailings and Mine Waste, Australian Centre for Geomechanics, Perth, pp. 251-260.

Sutar, H, Subash, CM, Santosh, KS, Ananta, PC \& Himanshu, SM 2014, 'Progress of red mud utilization: an overview', American Chemical Science Journal, vol. 4, no. 3, pp. 255-279.

The Irish Meteorological Service 2014, 30 year monthly and annual mean and extreme values for Shannon Airport 1961 to 1990 , The Irish Meteorological Service, Dublin, viewed 22 May 2014, http://www.met.ie/climate/shannonairport.asp 
Vick, SG 1990, Planning, design, and analysis of tailings dams, BiTech Publishers Ltd, Vancouver. 